\title{
Mapping the HLA diversity of the Iberian Peninsula
}

Iñigo Romòn ${ }^{1}$, Carmen Montes ${ }^{1}$, Dario Ligeiro ${ }^{2}$, Hélder Trindade ${ }^{2}$, Alicia Sanchez-Mazas ${ }^{3,4}$, José Manuel Nunes ${ }^{3,4}$, Stéphane Buhler ${ }^{3,5}$

${ }^{1}$ Histocompatibility Laboratory, Hematology and Transfusion Service, Hospital Universitario Marqués de Valdecilla - IFIMAV, Santander, Spain

2 Lisbon Center for Blood and Transplantation, Instituto Português de Sangue e Transplantação, IP, Lisbon, Portugal

${ }^{3}$ Laboratory of Anthropology, Genetics and Peopling history (AGP), Department of Genetics and Evolution - Anthropology Unit, University of Geneva, Switzerland

${ }^{4}$ Institute of Genetics and Genomics in Geneva (IGE3), Switzerland

5 Transplantation Immunology Unit and National Reference Laboratory for Histocompatibility (UIT/LNRH), Department of Genetic and Laboratory Medicine, Geneva University Hospital, Switzerland

Correspondence to: Iñigo Romòn (iromon@humv.es) or Stéphane Buhler (e-mail: stephane.buhler@unige.ch)

Key words: HLA, Iberian Peninsula, Spain, Portugal, human genetic diversity, bone marrow donors, registry, frequencies, haplotypes, linkage disequilibrium. 


\begin{abstract}
The polymorphism of HLA genes can be used to reconstruct human peopling history. However, this huge diversity impairs successful matching in stem cell transplantation, a situation which has led to the recruitment of millions of donors worldwide. In parallel to the increase of recruitment, registries are progressively relying on information from population genetics to optimize their donor pools in terms of HLA variability.

In this study, the HLA data of 65,000 Spanish bone marrow donors were analyzed together with 60,000 Portuguese individuals to provide a comprehensive HLA genetic map of the Iberian Peninsula.

The frequencies of many alleles were shown to vary continuously across the Peninsula, either increasing or decreasing from the Mediterranean coast to the Atlantic domain or from the Strait of Gibraltar to the Pyrenees and Bay of Biscay. Similar patterns were observed for several haplotypes. In addition, within some regions neighboring provinces share a close genetic similarity. These results outline the genetic landscape of the Iberian Peninsula, and confirm that the analysis of the HLA polymorphism may reveal relevant signatures of past demographic events even when data from donor registries are used. This conclusion stimulates future developments of the Spanish registry, presented here for the first time.
\end{abstract}




\section{Introduction}

The genes of the Major Histocompatibility Complex are the most polymorphic of the genome [1]. They encode cell surface molecules that are subdivided into two main functional classes, which play a key role in the immune response through the presentation of antigenic peptides to $\mathrm{T}$ cells. Their extreme level of polymorphism characterized by thousands of alleles described so far [2] coupled to a high number of loci to match between donors and recipients make the HLA complex largely responsible for graft rejection in hematopoietic stem cell and solid organ transplantation [3].

Patients who need hematopoietic stem cell transplantation (HSCT) often lack a HLA identical sibling because the chances of finding a HLA-matched related donor are low, i.e. around 30\% for patients of European descent [4]. Therefore, the possibility of finding volunteer unrelated donors (VUD) for HSCT with a high degree of HLA compatibility has stimulated the creation of national donor registries, which today have enrolled more than 25 million donors around the world (www.bmdw.org). However, despite the steady increase of VUD every year, a high percentage of patients still lack a suitable donor $[3,5]$. To improve the probability of finding a donor, the recruitment process thus needs to be optimized, e.g. by enlarging the donor database [6] or by refining donors' enrollment [7] using currently available information on HLA variability in different populations.

From the perspective of HSCT, it is important to know whether significant differences in HLA allele and haplotype frequencies exist between recruitment centers of a given country, because in such a case donor recruitment in different centers may provide a greater HLA diversity to the national registry, as has been shown in some countries [8-10], although not in others [11]. Moreover, HLA variation between different recruitment centers may be representative of regional diversity and used to reconstruct population migrations. Indeed, the patterns of HLA genetic relationships between populations usually reveal relevant signatures 
of past demographic events $[12,13]$, although HLA genes are also targets of natural selection due to their key role in immunity $[12,14]$. When criteria such as Hardy-Weinberg equilibrium are met, donor registries can thus provide excellent datasets to infer human peopling history because of the high number of HLA-typed individuals at several loci.

The Iberian Peninsula is located at the southwestern end of the Eurasian continental landmass. The Atlantic Ocean washes the North, West and South West of the Peninsula, while the Mediterranean Sea washes the East and South East. The Peninsula is very mountainous (Supplementary information S0); the Central Plateau is surrounded by mountain ridges in the north (the Pyrenees, the Iberic and the Cantabrian Ridge) and in the South (the Betic and Penibetic systems), thus conditioning the geographical isolation of some regions. The main language spoken in Spain is Spanish, but two romance languages (Catalan in the East and Galician in the West) and a language isolate (Euskera, or Basque in the Western Pyrenees) are also spoken. This cultural diversity represents an additional source of variability. In Portugal, only one main language is spoken, the Portuguese that, with the Galician, split during the $14^{\text {th }}$ century from the older Galician-Portuguese language spoken on all the northwestern region of the Iberian Peninsula.

The Iberian Peninsula was populated by early humans about 1 million years ago [15], but was repopulated by modern humans during the Upper Palaeolithic after their emergence from Africa, and by other population migrations during the Mesolithic and Neolithic periods. It was also occupied by Neanderthals [16]. The inhabitants of the Peninsula before the Roman conquest in the $3^{\text {rd }}$ century BC consisted of several populations, some of them of Celtic origin. Although the Romans left a profound influence, their numbers are supposed to have been scarce in proportion to the indigenous population [17]. After the fall of the Roman Empire, the Peninsula was invaded by Germanic tribes. In the 8th century AD, Arab Muslims came from Africa. Arabs conquerors were also few but had a durable influence in the region [18]. 
During the Middle Ages, the Christian kingdoms arising in the North reconquered territories under Muslim rule. During the following five centuries, Castile expelled the remnants of Muslim and Jewish populations [19], and did not receive any major inward population contributions, while massive emigration to America and to Europe took place [18]. Moreover, little population exchange took place between the Spanish kingdoms and Portugal. Massive emigration from rural to urban areas occurred during the 19th and 20th centuries [18]. In the last decades of the 20th century and the $21 \mathrm{st}$, the trend of migration has been reversed, with migrants reaching 10\% of the census (http://www.ine.es/inebaseDYN/cp30321/cp_inicio.htm; last accessed Jan 2016). While 5\% of migrants come from the European Union, especially from Romania, those from South American and African origin, especially Morocco, make 5\% of the census.

The Spanish registry of bone marrow donors (Registro español de donantes de médula ósea, REDMO) was created in the late 1980s by the "José Carreras Foundation" and manages the database of voluntary hematopoietic stem cell donors of Spain. In 2012 the National Transplant Organization (ONT) set out a Plan for the Donation of Bone Marrow. The goal was to obtain a breadth of Spanish donors representing the Spanish genetic composition whose typing might not be present in the international databases, therefore improving possibilities of finding compatible donors, and also reducing the dependence to foreign registries. In this study, the HLA molecular typings of a large subset of these Spanish donors were investigated, together with a panel of several thousand Portuguese individuals. The HLA variation in the whole Iberian Peninsula was mapped by combining classical population genetic analyses with geographic information approaches. This work is the first detailed analysis of the REDMO registry considered as a whole and it expands the analytical and graphical tools previously developed to analyze the HLA polymorphism in large datasets. 


\section{Material and Methods}

\section{HLA data from the Spanish bone marrow donor registry}

A total of 63,484 volunteer bone marrow donors from the REDMO registry were included in this study (data extracted on 07-13-2014). These data consisted in the molecular typings of donors at three HLA class I (A, B and C) and two class II (DQB1 and DRB1) loci, respectively (Supplementary information S1). The typings were provided at various levels of resolution. After careful examination using the SPLIT-TEST program (8), all the typings were automatically recoded to generic level of resolution for the analyses.

The ABO blood types of a subset of 28,596 donors were used to cross-validate the HardyWeinberg equilibrium (HWE) tests performed on multi-allelic HLA loci.

\section{HLA data from the Portuguese regional panel registry}

The generic HLA-A, B and DRB1 typings of a regional panel of 59,443 Portuguese were also analyzed in this study. This large panel of individuals was collected in all districts of the country (see below) and is included in the GENE[VA] database (hla-net.eu) and was recently studied as part of an extended collaborative project aimed at characterizing the patterns of HLA molecular diversity in Europe [20, 21].

\section{Regional information and geographic partitioning}

Spanish bone marrow donors are recruited by the health services in each of the 17 Autonomous Communities of Spain (administrative level 1, lands hereafter, Supplementary information S0, S1 and S2). They are recorded in the registry according to the province they reside in (administrative level 2). The geographic data extracted from the registry was thus the 
province of residence of each donor. No personal identification or demographic data were extracted. Only provinces in HWE and represented by at least 50 donors were considered for single-locus analyses and inter-regional comparisons. These criteria follow HLA-net recommendations [22]. A maximum of 48 Spanish provinces plus Andorra were retained, depending on the locus of interest (Figure 1, Supplementary information S1 and S2). In order to achieve reliable estimations and sufficient statistical power for multi-locus analyses, the data were grouped into lands (Supplementary information S0, S1 and S2).

The Portuguese individuals included in this study come from the 18 mainland districts of Portugal (Figure 1 and Supplementary information S2) and were selected according to the following criteria: residence in the district, Portuguese names and European descent for at least two generations. The data received were anonymous, the only information available for any given individual being its HLA type and its district of residence.

Spanish provinces and Portuguese districts were subdivided into 8 broad regions according both to their geographic proximity in the Iberian Peninsula and to historical data. This arbitrary regrouping was chosen to test whether the HLA diversity in the Peninsula reveals some geographic pattern or not in support to the other approaches envisaged above (Figure 1, Supplementary information S2).

\section{Statistical and GIS analyses}

Population genetic analyses were performed with the Gene[RATE] tools [20, 23], unless otherwise stated. Other summary statistics as well as graphs and maps were generated with $\mathrm{R}$ version 3.2.2 [24] using ggplot2 [25] and other useful geographic information packages.

Concerning the REDMO registry data, allele frequencies were estimated at the province and land levels. This was performed with an EM algorithm that assesses HWE using a nested likelihood procedure. Haplotype frequencies, global linkage disequilibrium (GLD), linkage 
disequilibrium (LD) for individual haplotypes as well as selective neutrality tests were performed at the land level, in order to work with larger sample sizes and hence avoid meaningless frequency estimates. All the intra-population analyses for the Portuguese districts were already available $[20,21]$ and were incorporated into the current study to perform interregional comparisons with Spanish data. At each locus, gene diversity was assessed within provinces/districts by the expected heterozygosity $\left(\mathrm{H}_{\mathrm{exp}}\right)$. Analysis of Variance (ANOVA) was performed with Arlequin [26] to test the significance of the variance components associated to three levels of genetic structure: among provinces/districts ( $\mathrm{F}_{\mathrm{ST}}$ ), among provinces/districts within the 8 predefined geographic broad regions of the peninsula $\left(\mathrm{F}_{\mathrm{SC}}\right)$, and among these predefined regions $\left(\mathrm{F}_{\mathrm{CT}}\right)$, respectively. Prevosti genetic distances [27] were computed between the provinces/districts and plotted using non-metric multidimensional scaling analyses (NMDS; [28]). Genetic distances were compared to logarithms of arc geographic distances with two-way Mantel tests [29]. Spearman's correlation coefficients between allele frequencies, $\mathrm{H}_{\text {exp }}$, NMDS axes and either latitude or longitude coordinates were estimated at each locus. The coordinates of each Spanish province or Portuguese district were retrieved from Getty Thesaurus of Geographic Names ${ }^{\circledR}$ Online (http://www.getty.edu/research/tools/vocabularies/tgn/index.html).

\section{Results}

\section{Gene diversity, Hardy-Weinberg equilibrium and selective neutrality}

Gene diversity is close to its maximal value of 1 (i.e. an excess of heterozygotes, see neutrality tests hereafter) at HLA-A (0.816-0.891), B (0.895-0.932), C (0.859-0.903) and DRB1 (0.864-0.891), and exhibits lower values at HLA-DQB1 (0.721-0.7655, Supplementary information S3). Although values are very close among provinces/districts, a weak but yet 
significant correlation is retrieved between $\mathrm{H}_{\exp }$ and latitude at HLA-A, B, C and DRB1, on the one hand ( $\mathrm{B}$ and $\mathrm{C}$ remaining significant after correction), and between $\mathrm{H}_{\exp }$ and longitude at HLA-B and DRB1, on the other hand (DRB1 remaining significant after correction, Table 1a). Sample size does not appear to be a main factor in these observations (Supplementary information S4). The null hypothesis of HWE is not rejected in almost every Spanish province or land (Supplementary information S1). After cross validation with ABO data (for which HWE is never rejected, Supplementary information S1), the decision was made that provinces or lands rejecting HWE with a p-value $<0.001$ would not be considered in further analyses at the given HLA locus. These cases are Madrid at HLA-A, B and C and Andalucía at HLA-A. In accordance with the high values of heterozygosity reported, neutrality is rejected toward an excess of heterozygotes at all loci (Supplementary information S5).

\section{Allele frequencies}

The HLA allele frequencies are listed in Supplementary information S6 and plotted in Supplementary information S7. Among the 28 alleles that exhibit frequency differences greater than $5 \%$ in at least 10 pairs of provinces/districts (Figure 2), a significant correlation with latitude is found for $\mathrm{A}^{*} 24, \mathrm{C} * 07, \mathrm{C} * 12$, DRB1*07 and DRB1*11 and with longitude for $A * 29, A^{*} 30, B^{*} 07, B^{*} 18, B^{*} 35, B^{*} 44, B^{*} 51, \mathrm{DRB} 1 * 03, \mathrm{DRB} 1 * 04, \mathrm{DRB} 1 * 07, \mathrm{DRB} 1 * 13$ and DRB1*15 (Holm's adjusted p-values in Table 1b). The frequencies either decrease (e.g. $\mathrm{B} * 44, \mathrm{DRB} 1 * 07)$ or increase (e.g. $\mathrm{B} * 51, \mathrm{DRB} 1 * 13)$ from the Mediterranean coast to the Atlantic domain. Conversely, the frequencies of some alleles increase (e.g. DRB1*07) or decrease (e.g. DRB1*11) from the Strait of Gibraltar to the Bay of Biscay and the Pyrenees. Other less frequent alleles, e.g. $\mathrm{A} * 23, \mathrm{~B} * 27, \mathrm{~B} * 40$ and $\mathrm{B} * 50$, also exhibit a significant correlation with either latitude or longitude (Table 1b). 


\section{GLD, haplotype frequencies and LD}

We tested global linkage disequilibrium (GLD) for 7 pairs of loci, i.e. A B, A C, A DRB1, B C , B DRB1, C $\sim$ DRB1 and DRB1 DQB1. As shown in Supplementary information S8, a highly significant GLD is detected for each pair in all lands/districts (except in Portuguese from Bragança at A DRB1). Haplotype frequencies reaching a minimum of $1 \%$ in at least 3 lands/districts were reported for the same 7 pairs of loci with indication of significant LD (Supplementary information S9 and S10). Figure 3 presents the most common haplotypes in the Iberian Peninsula (except for C DRB1, see Supplementary information S10), their geographic distribution according to the 8 broad regions and their LD significance. A regional pattern is detected for $\mathrm{A} * 02 \sim \mathrm{B} * 51, \mathrm{~A}^{*} 03 \sim \mathrm{B} * 07, \mathrm{~A} * 29 \sim \mathrm{B} * 44, \mathrm{~A} * 30 \sim \mathrm{B} * 08, \mathrm{~A} * 29 \sim \mathrm{DRB} 1 * 07$, $\mathrm{A} * 30 \sim \mathrm{DRB} 1 * 03, \mathrm{~B} * 07 \sim \mathrm{DRB} 1 * 15, \mathrm{~B} * 18 \sim \mathrm{DRB} 1 * 03$ and $\mathrm{B} * 44 \sim \mathrm{DRB} 1 * 07$ with Portuguese districts and Galicia located at one end of the frequency spectrum (either the lower or the upper end) and Euskadi, Navarra and La Rioja at the other. Other Spanish lands often show intermediate frequencies, sometimes with a visible regrouping into broad geographic region (e.g. region 7 for $\mathrm{A} * 29 \sim \mathrm{B} * 44, \mathrm{~A} * 30 \sim \mathrm{DRB} 1 * 03$ and $\mathrm{B} * 07 \sim \mathrm{DRB} 1 * 15)$.

With a few exceptions, the haplotypes reported on Figure 3 are in very strong and highly significant LD across the whole Peninsula for A B, B DRB1, B C and DRB1 DQB1. In contrast, several of the most common haplotypes observed for A DRB1 and for A C are not in significant LD.

\section{Genetic comparisons at the regional level}

Genetic distances were estimated among provinces/districts of the Peninsula and are plotted on Figure 4 (detailed NMDS plots in Supplementary information S11). Except for HLADQB1 where no clear geographic pattern is observed, some regional clustering is evidenced on the plots for HLA-A, B, DRB1 and, to a lesser extent, HLA-C. Concerning HLA-A, B and 
DRB1, the Portuguese districts and Galician provinces (region 1) are projected close to each other and to the neighboring Andalusian province of Huelva (from region 2). Provinces of region 5 (Euskadi, Navarra and La Rioja) and Cantabria (from region 4) are clustered together and are clearly apart from region 1 . The Mediterranean coastal provinces of region 7 are projected in the middle of the scatterplots next to the provinces of Andalusia (region 2), except for Huelva. By contrast, provinces of Aragon (region 6), Canarias (region 8) and from the center of Spain (region 3) are more spread across the plots. Concerning HLA-C, some regional clusters are observed, but no Portuguese data and less Spanish provinces are represented at this locus, like HLA-DQB1.

The relationship with geography observed on the NMDS plots is confirmed by the significant correlation found between genetic and geographic distances at HLA-A, B, C and DRB1 (Table 2, with $\mathrm{A}, \mathrm{B}$ and $\mathrm{DRB} 1$ remaining significant after correction). When restricting the analysis to the provinces of Spain represented at all 5 loci, the correlation remains significant (after correction) for HLA-B and C and is not significant for HLA-A, DRB1 and DQB1 (Table 2). The singularity of HLA-DQB1 in regards to geography thus cannot be explained by the heterogeneous representation of provinces and districts among loci. Moreover, a significant correlation between latitude and longitude coordinates and one or both NMDS axes is found at HLA-A, B, C and DRB1 (Table 1c).

In line with these results, hierarchical analyses of variance reveal a low but significant structure in the Peninsula, except at HLA-DQB1 (Table 3, i.e. variation among regions $\left(\mathrm{F}_{\mathrm{CT}}\right)$ is significant and greater than variation among populations within regions $\left(\mathrm{F}_{\mathrm{SC}}\right)$ ). Moreover, pairwise comparisons suggest that regions 1 and 2 and, to a lesser extent, 5 and 7 form differentiated clusters (Supplementary information S12).

\section{Discussion}


In this study, we have analyzed the HLA data of numerous donors from the Spanish bone marrow donor registry and coupled our analysis with another large dataset from Portugal to gain a better insight of the genetic complexity of the Iberian Peninsula. Previously, only HLA data from peculiar Spanish populations [30-36] and from disease association studies [37-40] had been published and the whole REDMO dataset is here analyzed for the first time. Unfortunately, some sparsely populated provinces (Soria, Zamora and Huesca) could not be analyzed due to a lack of sufficient donors. Also, Madrid, which as a capital, represents a meeting point from people from the whole country and abroad, deviated from Hardy Weinberg equilibrium due to its genetic heterogeneity and was not included in some analyses. However, except for these provinces, our results show that the HLA allele frequencies estimated on REDMO donors are very similar to those obtained on Spanish populations analyzed in other studies (from Castilla Leon, Cataluña-Girona, Euskadi-Guipuzcoa and Murcia, Supplementary information S13). This plays in favor of considering registry data in population genetic studies when appropriate quality criteria are met.

This study disclosed a genetic similarity between the provinces and districts of the Atlantic domain, which probably reflects the proximity between Portuguese and Galician languages [41] and the history in this part of the Peninsula [18]. The same can be said for the genetic similarity observed between the Basque Country, Navarre and La Rioja, as they share a geographical niche (the higher Ebro Valley) as well as common history and language. Of note, Basques do not exhibit marked differences in their HLA frequencies compared to other Spanish regions, apart from being well differentiated from the provinces of the Atlantic domain, as they are well integrated in the general continuum of variation observed in the Peninsula. These findings are concordant with other genetic markers [42]. The Catalan and 
Valencian Communities and the provinces of Andalucía, in the Mediterranean coast, are also genetically close.

Interestingly, a total of 25 HLA alleles revealed a frequency variation significantly correlated to geography in the Peninsula (Table 1). Actually, to the exception of HLA-A*30, A*68 and $C^{*} 07$, the frequency of the other 22 alleles were previously shown by spatial autocorrelation analysis to vary along frequency clines or depressions in Europe [21]. Among the alleles listed in Table $1, \mathrm{~A}^{*} 23, \mathrm{~B}^{*} 07, \mathrm{~B}^{*} 14, \mathrm{~B}^{*} 40$ and $\mathrm{B}^{*} 50$ exhibit frequency clines that may represent genetic signatures of population migrations from central Europe to Spain and Portugal that occurred during the Neolithic [43] and/or more ancient periods of time. Conversely, the remaining 17 alleles showing a significant but more restricted frequency variation may reflect historical events that directly took place within the Iberian Peninsula or are signatures of other migrations (e.g. maritime colonization around the Mediterranean Sea or via Northern Africa). For instance, HLA-B*51 exhibits an increase of frequency going from the Mediterranean Sea to the Atlantic coast of the Iberian Peninsula, while its frequency increases going from Northwestern to Southeastern Europe when looking at the continental scale. HLA-DRB $1 * 07$ frequency increases from the Southwestern/Central to the Northeastern part of the Peninsula, while the continental variation of this allele is defined by marked differences around the Alps with higher frequencies in Central-Western and North-Eastern Europe compared to the Balkans.

The genetic variation among regions of the Iberian Peninsula is rather low ( $\mathrm{F}_{\text {ST }}$ up to $0.16 \%$ ) and similar to the levels previously found in the Swiss blood stem cell registry [8] and HemaQuebec [9]. However, a significant genetic structure is observed at all loci (except DQB1), indicating a genetic complexity that was also ascertained with other genetic markers [44-46]. For example, a study using hundred thousand SNPs revealed significant patterns of structure among distant locations in Spain [45]. The concordance between HLA and SNPs had already 
been described elsewhere [21], a few HLA loci turning out to provide an equivalent information to huge numbers of bi-allelic SNPs distributed across the whole genome. Note also that we are here working with the lowest resolution level of HLA molecular typing, and complementary information to the broad patterns of genetic variation revealed in the present study is expected to be assessed through analyses at higher resolution levels [12, 47]. In particular, patterns of linkage disequilibrium between alleles defined at high resolution would be much more informative (in case of sufficient sample size and statistical power) than restricting the analysis to generic specificities, as alleles within those are not necessarily defined by the same preferential associations (e.g. DRB1*13:01 DQB1*06:03 and DRB1*13:03 DQB1*03:01 in European populations).

While HLA matching is still performed on the basis of low resolution typing for solid organ transplantation [3], the relevance of high resolution typing of both donors and recipients is currently debated $[48,49]$. In bone marrow transplantation, the matching is systematically performed on the basis of high resolution typing when unrelated donors are selected [3]. In this sense, the current low resolution snapshot of the HLA diversity among REDMO donors represents a preliminary characterization but is still very useful to optimize future recruitment strategies. Given the complex genetic landscape detected in Spain, we confirm the need to increase the recruitment efforts of the Spanish registry if donors are to be found in a timely way for transplant and if self-sufficiency is to be improved. Although the percentage of nonrelated donations has increased steeply from 5\% in 2012 to $11.5 \%$ in 2015 (REDMO, personal communication), these data are very far from those of other registries. The current decentralized recruitment in all provinces of the country is judicious, but will benefit from the current work showing the necessity for regional authorities to implement local strategies to increase donor numbers. For instance, Andalucía, Barcelona and Madrid comprise close to 
$60 \%$ of the total donors, while they only comprise up to $45 \%$ of the total Spanish population (http://www.ine.es/inebaseDYN/cp30321/cp_inicio.htm; last accessed Jan 2016). Increasing the recruitment in poorly represented provinces (e.g. from Aragon, Castilla Leon and Extremadura) or in provinces appearing to contribute the most to the regional level of variation (e.g. from Euskadi and Galicia) would enhance self-sufficiency and the chances of finding Spanish donors for patients in need of a transplant. Because of the stringent requirements for HSCT, another future crucial improvement would be to include allele typing in order to better depict the donor's HLA diversity in the registry. Besides, the minimum requirements for typing at HLA-A, B and DRB1 make the research of unrelated donors for a given patient difficult to implement. A more ambitious strategy, typing more loci at a higher resolution level, would provide a much more accurate picture, and help donor recruitment with the refined information without excessive additional expenses. Cost increase could be covered at least in part by more successful donor searches.

Our data collation could also be used for other purposes, like solid organ transplantation. The systematic donor analysis presented here could be a base for a Spanish virtual Panel Reactive Antibody tool (vPRA), thus helping in the organ assignment for hyper sensitized donors.

In conclusion, this meta-analysis revealed a low but significant genetic structure among broad geographic regions of the Iberian Peninsula. Besides genetic signatures of trans-European migrations, local patterns were disclosed and might be tentatively explained by the complex geographic landscape of the Peninsula favoring the isolation of some regions, although the general profile of variation was mostly continuous along main geographic axes. In addition, a close genetic relationship between provinces sharing a common linguistic background was observed, suggesting a significant influence of the cultural (linguistic) diversity in Spain and Portugal. Overall, a comprehensive map of the HLA diversity in the Peninsula could be drawn 
and will be most useful for ongoing European collaborative projects. Finally, this analysis of the Spanish bone marrow donor registry will be helpful for the Spanish health authorities to make decisions on the maintenance and expansion of the registry according to HLA criteria.

\section{Acknowledgments}

The authors thank the REDMO and ONT staffs for their continuous support. This work was supported by the Swiss National Science Foundation (grant \#31003A_144180 to ASM) and by COST Action BM0803. 


\section{References}

[1] Mungall AJ, Palmer SA, Sims SK, Edwards CA, Ashurst JL, Wilming Let al. : The DNA sequence and analysis of human chromosome 6. Nature 2003;425:805.

[2] Robinson J, Halliwell JA, Hayhurst JD, Flicek P, Parham P, Marsh SGE: The IPD and IMGT/HLA database: allele variant databases. Nucleic Acids Research 2015;43:D423.

[3] Tiercy JM, Claas F: Impact of HLA diversity on donor selection in organ and stem cell transplantation. Hum Hered 2013;76:178.

[4] Appelbaum FR: Allogeneic Hematopoietic Cell Transplantation for Acute Myeloid Leukemia When a Matched Related Donor Is Not Available. ASH Education Program Book 2008;2008:412.

[5] Tiercy JM: Unrelated Hematopoietic Stem Cell Donor Matching Probability and Search Algorithm. Bone Marrow Research 2012;2012.

[6] Kollman C, Abella E, Baitty RL, Beatty PG, Chakraborty R, Christiansen CLet al. : Assessment of optimal size and composition of the U.S. National Registry of hematopoietic stem cell donors. Transplantation 2004;78:89.

[7] Johansen KA, Schneider JF, McCaffree MA, Woods GL: Efforts of the United States' National Marrow Donor Program and Registry to improve utilization and representation of minority donors. Transfus Med 2008;18:250.

[8] Buhler S, Nunes JM, Nicoloso G, Tiercy J-M, Sanchez-Mazas A: The Heterogeneous HLA Genetic Makeup of the Swiss Population. PLoS ONE 2012;7:e41400.

[9] Buhler S, Nunes JM, Sanchez-Mazas A, Richard L: HLA-A, B and DRB1 genetic heterogeneity in Quebec. International Journal of Immunogenetics 2015:n/a.

[10] Schmidt AH, Solloch UV, Baier D, Stahr A, Wassmuth R, Ehninger Get al. : Regional differences in HLA antigen and haplotype frequency distributions in Germany and their relevance to the optimization of hematopoietic stem cell donor recruitment. Tissue Antigens 2010;76:362.

[11] Schmidt AH, Solloch UV, Pingel J, Sauter J, Böhme I, Cereb Net al. : Regional HLA Differences in Poland and Their Effect on Stem Cell Donor Registry Planning. PLoS ONE 2013;8:e73835.

[12] Buhler S, Sanchez-Mazas A: HLA DNA Sequence Variation among Human Populations: Molecular Signatures of Demographic and Selective Events. PLoS ONE 2011;6:e14643.

[13] Sanchez-Mazas A, Fernandez-Viña M, Middleton D, Hollenbach JA, Buhler S, Di Det al. : Immunogenetics as a tool in anthropological studies. Immunology 2011;133:143.

[14] Solberg OD, Mack SJ, Lancaster AK, Single RM, Tsai Y, Sanchez-Mazas Aet al. : Balancing selection and heterogeneity across the classical human leukocyte antigen loci: a metaanalytic review of 497 population studies. Hum Immunol 2008;69:443.

[15] Carbonell E, Bermudez de Castro JM, Pares JM, Perez-Gonzalez A, Cuenca-Bescos G, Olle Aet al. : The first hominin of Europe. Nature 2008;452:465.

[16] Lalueza-Fox C, Sampietro ML, Caramelli D, Puder Y, Lari M, Calafell Fet al. : Neandertal evolutionary genetics: mitochondrial DNA data from the iberian peninsula. Mol Biol Evol 2005;22:1077.

[17] McEvedy C, Jones R: Atlas of wold population history. London, United Kingdom: Penguin Books Ltd; 1978.

[18] García de Cortázar F: Atlas de Historia de España. Madrid, Spain: Editorial Planeta; 2005.

[19] Adams SM, Bosch E, Balaresque PL, Ballereau SJ, Lee AC, Arroyo Eet al. : The genetic legacy of religious diversity and intolerance: paternal lineages of Christians, Jews, and Muslims in the Iberian Peninsula. Am J Hum Genet 2008;83:725.

[20] Nunes JM, Buhler S, Roessli D, Sanchez-Mazas A, the HLAnc: The HLA-net GENE[RATE] pipeline for effective HLA data analysis and its application to 145 population samples from Europe and neighbouring areas. Tissue Antigens 2014;83:307.

[21] Sanchez-Mazas A, Buhler S, Nunes JM: A New HLA Map of Europe: Regional Genetic Variation and Its Implication for Peopling History, Disease-Association Studies and Tissue Transplantation. Human Heredity 2013;76:162. 
[22] Sanchez-Mazas A, Vidan-Jeras B, Nunes JM, Fischer G, Little AM, Bekmane Uet al. : Strategies to work with HLA data in human populations for histocompatibility, clinical transplantation, epidemiology and population genetics: HLA-NET methodological recommendations. International Journal of Immunogenetics 2012;39:459.

[23] Nunes JM: Using UNIFORMAT and GENE[RATE] to Analyze Data with Ambiguities in Population Genetics. Evolutionary Bioinformatics 2015;Suppl. 2:19.

[24] R-core-team: R: A language and environment for statistical computing. R Foundation for Statistical Computing, Vienna, Austria 2013.

[25] Wickham H: ggplot2. New York, NY: Springer; 2009.

[26] Excoffier L, Laval G, Schneider S: Arlequin ver. 3.0: An integrated software package for population genetics data analysis. Evolutionary Bioinformatics Online 2005;1:47.

[27] Prevosti A, Ocaña J, Alonso G: Distances between populations of drosophila subobscura based on chromosome arrangement frequencies. Theoretical and applied genetics 1975;45:231.

[28] Kruskal JB: Nonmetric multidimensional scaling: a numerical method. Psychometrika 1964;29:115.

[29] Mantel G: The detection of disease clustering and a generalized regression approach. Cancer research 1967;27:209.

[30] Alcoceba M, Marín L, Balanzategui A, Sarasquete ME, Chillón MC, Martín-Jiménez Pet al. : Frequency of HLA-A, -B and -DRB1 specificities and haplotypic associations in the population of Castilla y León (northwest-central Spain). Tissue Antigens 2011;78:249.

[31] Comas D, Mateu E, Calafell F, Pérez-Lezaun A, Bosch E, Martínez-Arias Ret al. : HLA class I and class II DNA typing and the origin of Basques. Tissue Antigens 1998;51:30.

[32] Martinez-Laso J, De Juan D, Martinez-Quiles N, Gomez-Casado E, Cuadrado E, Arnaiz-Villena $A$ : The contribution of the HLA-A, $-B,-C$ and $-D R$, -DQ DNA typing to the study of the origins of Spaniards and Basques. Tissue Antigens 1995;45:237.

[33] Muro M, Marín L, Torío A, Moya-Quiles MaR, Minguela A, Rosique-Roman Jet al. : HLA polymorphism in the murcia population (Spain): in the cradle of the archaeologic Iberians. Human Immunology 2001;62:910.

[34] Riccio ME, Buhler S, Nunes JM, Vangenot C, Cuénod M, Currat Met al. : 16th IHIW: Analysis of HLA Population Data, with updated results for 1996 to 2012 workshop data (AHPD project report). International Journal of Immunogenetics 2013;40:21.

[35] Sánchez-Velasco P, Escribano de Diego J, Paz-Miguel JE, Ocejo-Vinyals G, Leyva-Cobián F: HLA-DR, DQ nucleotide sequence polymorphisms in the Pasiegos (Pas valleys, Northern Spain) and comparison of the allelic and haplotypic frequencies with those of other European populations. Tissue Antigens 1999;53:65.

[36] Sanchez-Velasco P, Gomez-Casado E, Martinez-Laso J, Moscoso J, Zamora J, Lowy Eet al. : HLA alleles in isolated populations from North Spain: origin of the Basques and the ancient Iberians. Tissue Antigens 2003;61:384.

[37] Conde-Jaldón M, Montes-Cano MA, García-Lozano JR, Ortiz-Fernández L, Ortego-Centeno N, González-León Ret al. : Epistatic Interaction of ERAP1 and HLA-B in Behçet Disease: A Replication Study in the Spanish Population. PLOS ONE 2014;9:e102100.

[38] Donat E, Planelles D, Capilla-Villanueva A, Montoro JA, Palau F, Ribes-Koninckx C: Allelic distribution and the effect of haplotype combination for HLA type II loci in the celiac disease population of the Valencian community (Spain). Tissue Antigens 2009;73:255.

[39] Fernández O, R-Antigüedad A, Pinto-Medel MJ, Mendibe MM, Acosta N, Oliver Bet al. : HLA class II alleles in patients with multiple sclerosis in the Biscay province (Basque Country, Spain). Journal of Neurology 2009;256:1977.

[40] Romero-Pinel L, Pujal JM, Martínez-Yélamos S, Gubieras L, Matas E, Bau Let al. : HLA-DRB1: genetic susceptibility and disability progression in a Spanish multiple sclerosis population. European Journal of Neurology: The Official Journal of the European Federation of Neurological Societies 2011;18:337. 
[41] Lewis MP, Gary FS, Charles DF: Ethnologue: Languages of the World, Eighteenth edition. Online version: http://www.ethnologue.com. Dallas, Texas; 2015.

[42] Laayouni $\mathrm{H}$, Calafell $\mathrm{F}$, Bertranpetit J: A genome-wide survey does not show the genetic distinctiveness of Basques. Human Genetics 2010;127:455.

[43] Cruz Berrocal M: The Early Neolithic in the Iberian Peninsula and the Western Mediterranean: A Review of the Evidence on Migration. J World Prehist 2012;25:123.

[44] Ambrosio B, Hernández C, Novelletto A, Dugoujon JM, Rodríguez JN, Cuesta Pet al. : Searching the peopling of the Iberian Peninsula from the perspective of two andalusian subpopulations: a study based on Y-chromosome haplogroups J and E. Collegium Antropologicum 2010;34:1215.

[45] Gayán J, Galan JJ, González-Pérez A, Sáez ME, Martínez-Larrad MT, Zabena Cet al. : Genetic Structure of the Spanish Population. BMC Genomics 2010;11:326.

[46] Hernández CL, Reales G, Dugoujon J-M, Novelletto A, Rodríguez JN, Cuesta Pet al. : Human maternal heritage in Andalusia (Spain): its composition reveals high internal complexity and distinctive influences of mtDNA haplogroups $U 6$ and $L$ in the western and eastern side of region. BMC Genetics 2014;15:11.

[47] Sanchez-Mazas A, Meyer D: The Relevance of HLA Sequencing in Population Genetics Studies. Journal of Immunology Research 2014;2014:e971818.

[48] Cecka JM, Reed EF, Zachary AA: HLA High-Resolution Typing for Sensitized Patients: A Solution in Search of a Problem? American Journal of Transplantation 2015;15:855.

[49] Duquesnoy RJ, Kamoun M, Baxter-Lowe LA, Woodle ES, Bray RA, Claas FHJet al. : Should HLA Mismatch Acceptability for Sensitized Transplant Candidates Be Determined at the HighResolution Rather Than the Antigen Level? American Journal of Transplantation 2015;15:923. 


\section{Figure legends}

Figure 1 Spanish provinces and Portuguese districts included in the analyses and sample sizes at each locus after removing the provinces where $\mathrm{n} \leq 50$ donors and/or HWE $\mathrm{p}$-value $<0.001$. The subdivision of the Iberian Peninsula into 8 broad geographic regions is indicated by colors. Region 1: Portugal districts and Galicia; region 2: Andalucía; region 3: Castilla Leon, Castilla La Mancha, Extremadura and Madrid; region 4: Asturias and Cantabria; region 5: Euskadi, Navarra and La Rioja; region 6: Aragon; region 7: Andorra, Baleares, Cataluña, Murcia and Valencia; region 8: Canarias (not shown on the map).

Figure 2 Geographic information maps of the HLA allele frequencies distributions in the Iberian Peninsula. The alleles shown are characterized by frequency differences of $5 \%$ or more in at least 10 pairwise comparisons among both Spanish provinces and Portuguese districts. Provinces not included in the analysis are shown in white (no data available, small sample size or HWE rejection), while provinces from region 8 (Canarias) are not shown.

Figure 3 Haplotypes frequencies ( $\geq 3 \%$ in at least 3 Spanish lands or Portuguese districts) and linkage disequilibrium (assessed by standardized residuals) for $\mathrm{A} \sim \mathrm{B}, \mathrm{A} \sim \mathrm{C}, \mathrm{A} \sim \mathrm{DRB} 1, \mathrm{~B} \sim \mathrm{C}$, B DRB1 and DRB1 DQB1 loci pairs. Crosses indicate that the standardized residual is smaller than 2 (i.e. a non-significant linkage disequilibrium). The subdivision of the Iberian Peninsula into 8 broad geographic regions is indicated by colors and the number of Spanish lands and Portuguese districts is reported on the plots. Note that each plot uses its own scale for sake of visibility.

Figure 4 Two dimensional NMDS plots for locus HLA-A, B, C, DRB1 and DQB1 (stress values are $0.16,0.16,0.2,0.16$ and 0.15 , respectively). The subdivision of the Iberian Peninsula into 8 broad geographic regions is indicated by colors. 

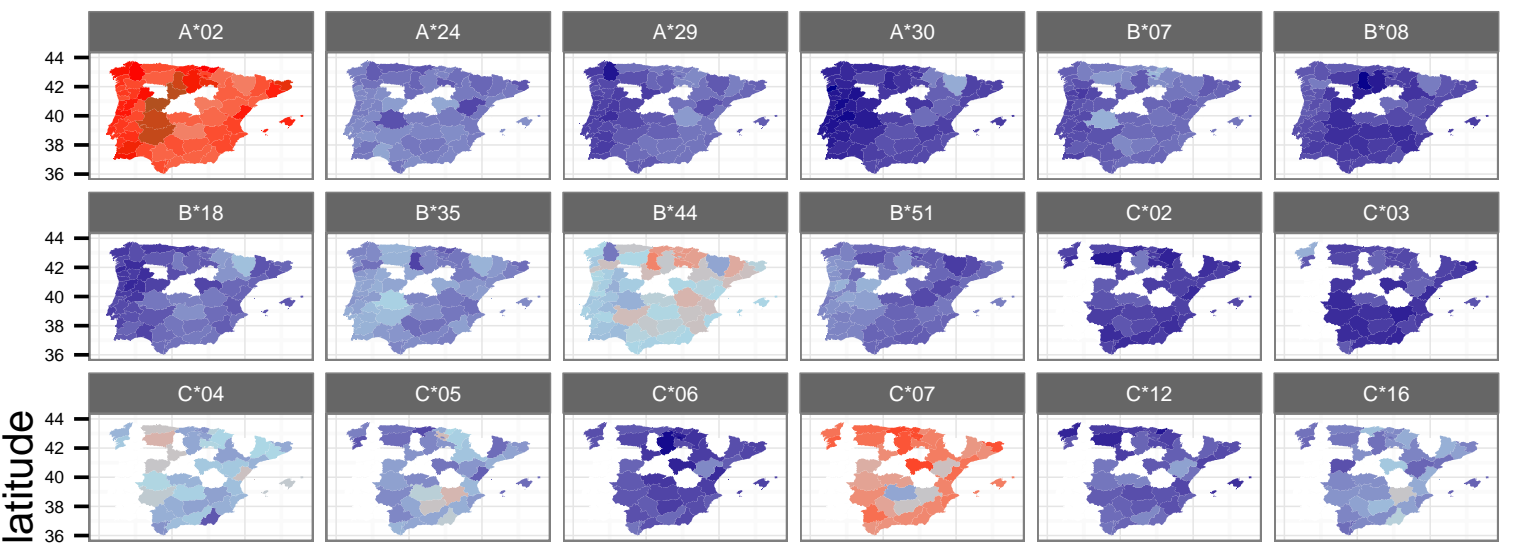

Frequency
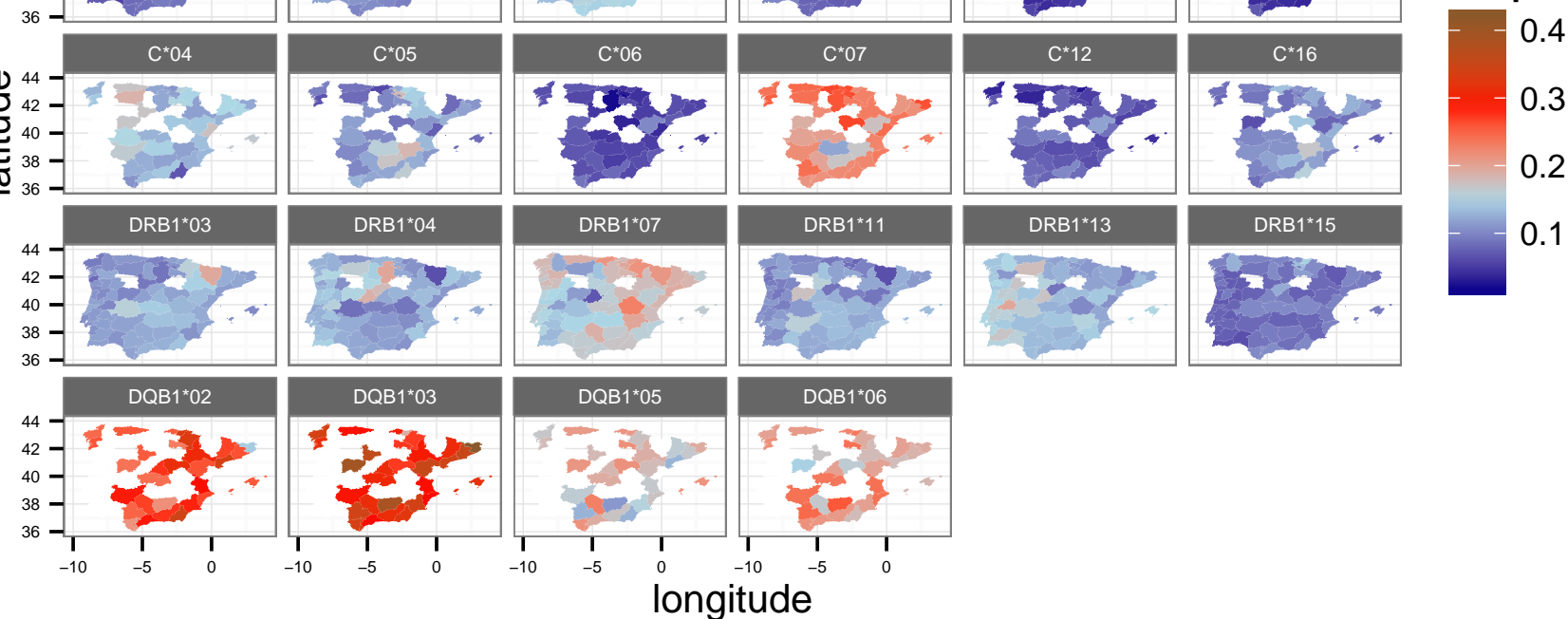

0.4
0.3
0.2
0.1




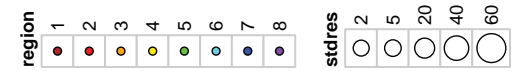

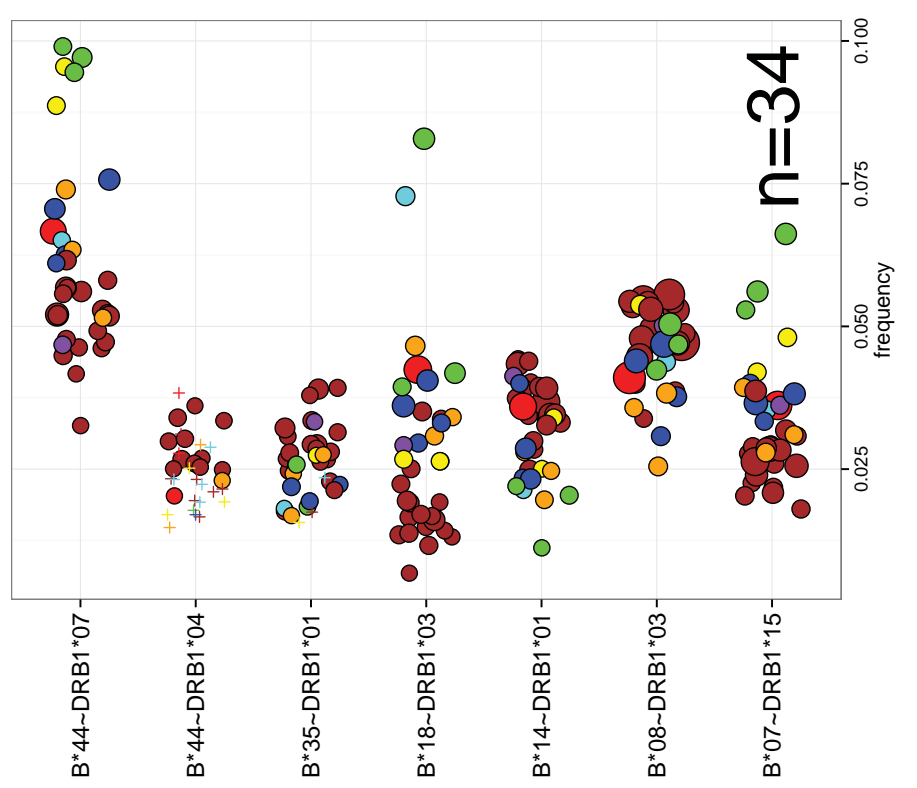

ตูต้ำ

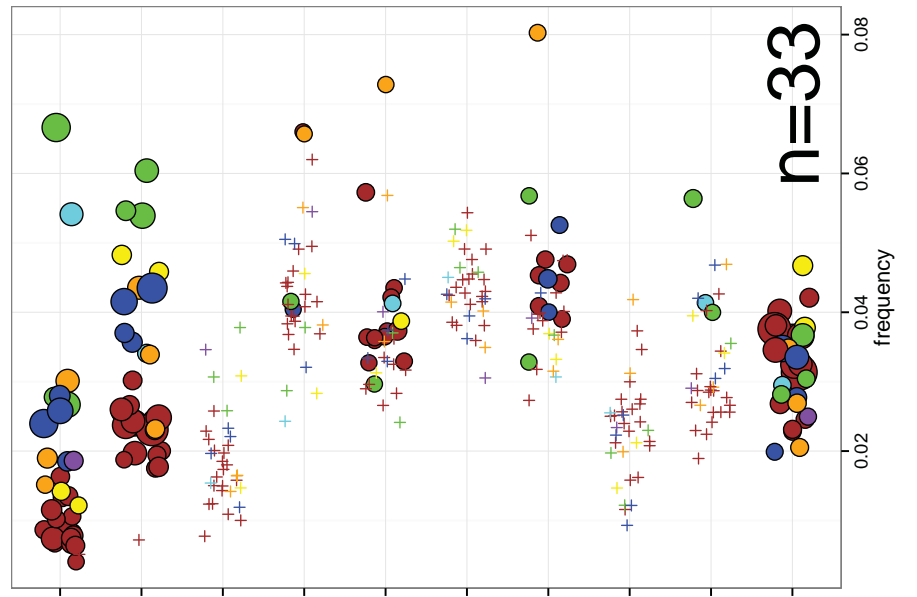

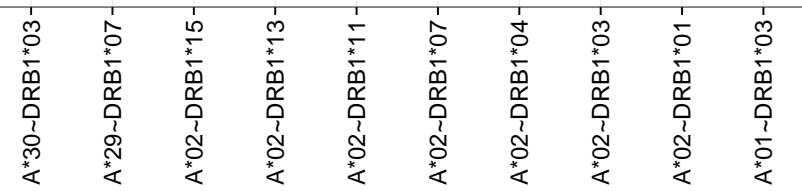

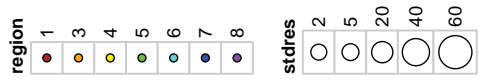

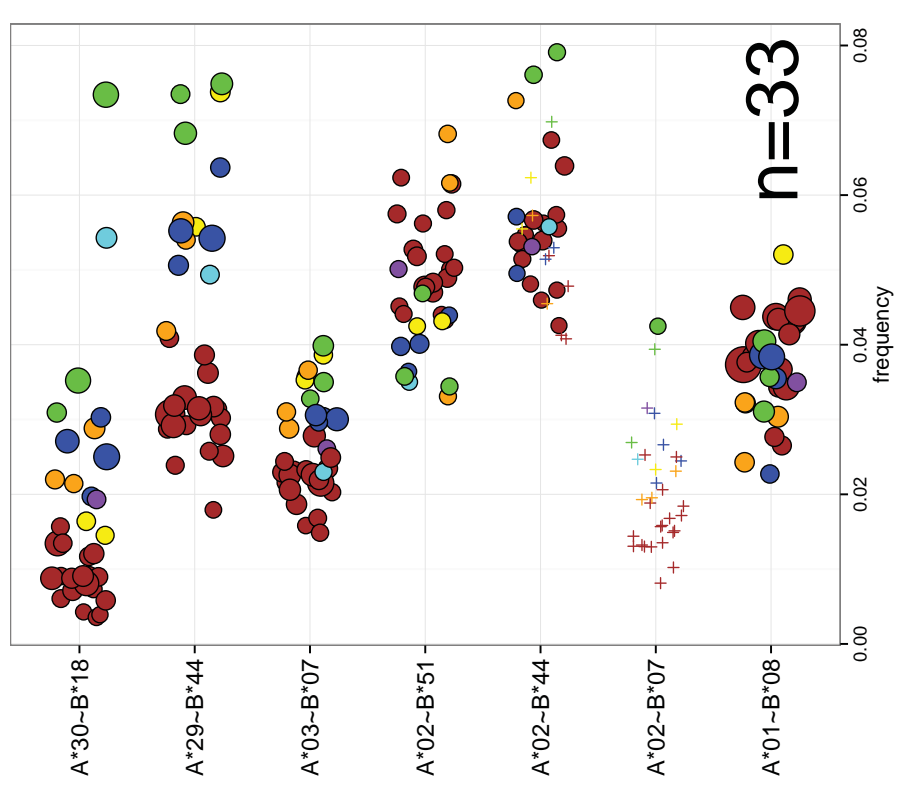

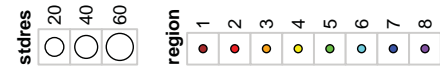

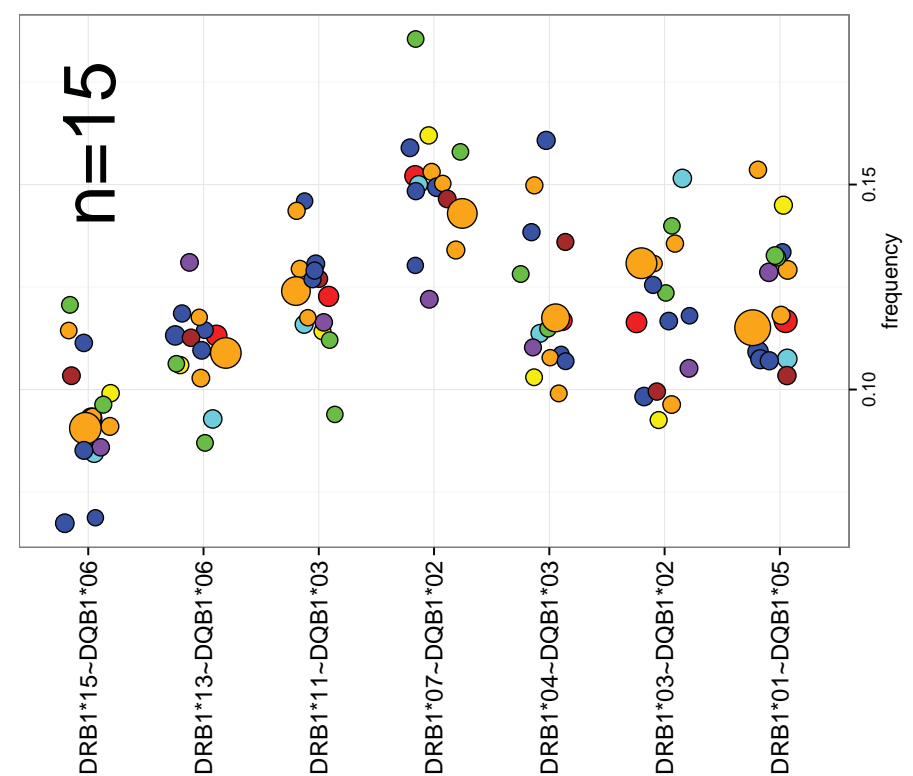

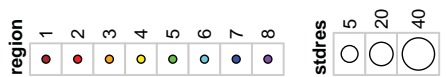

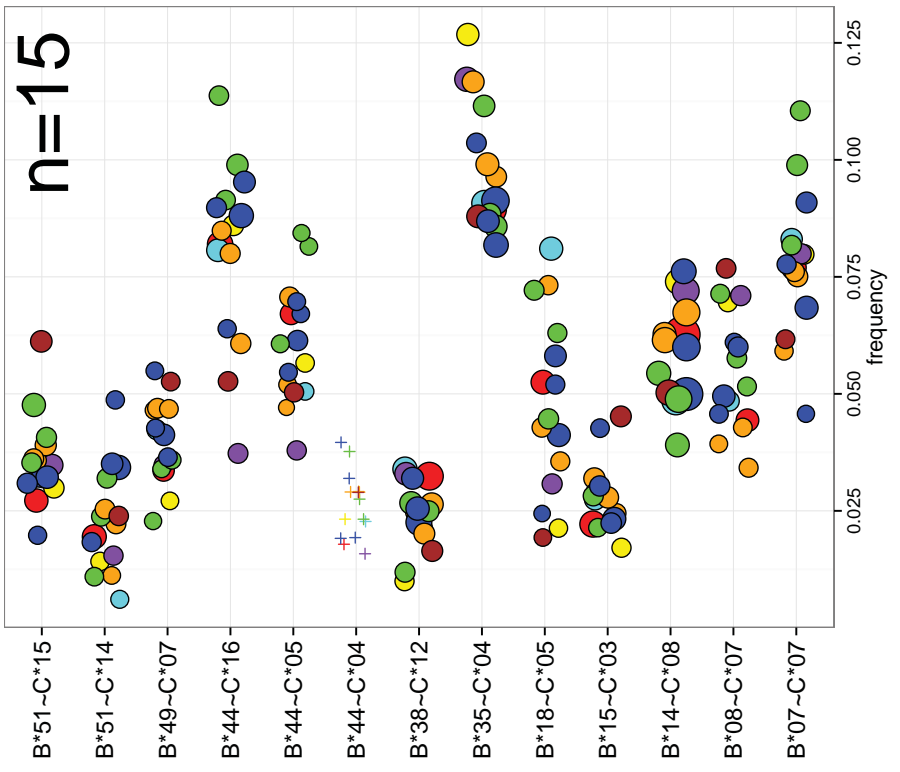

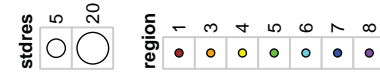

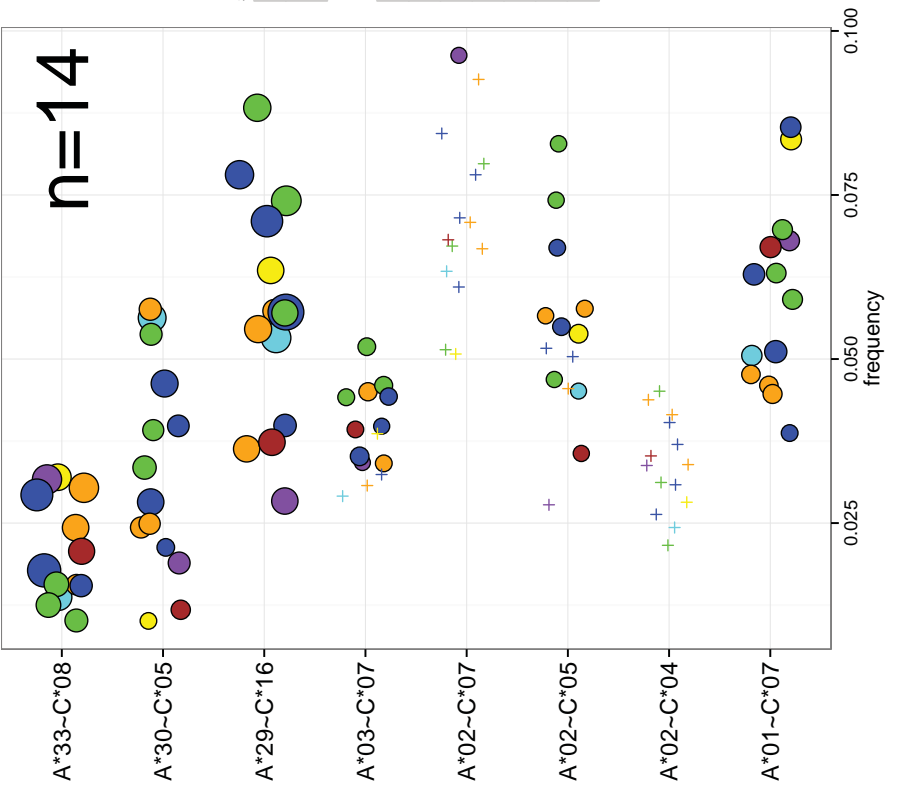




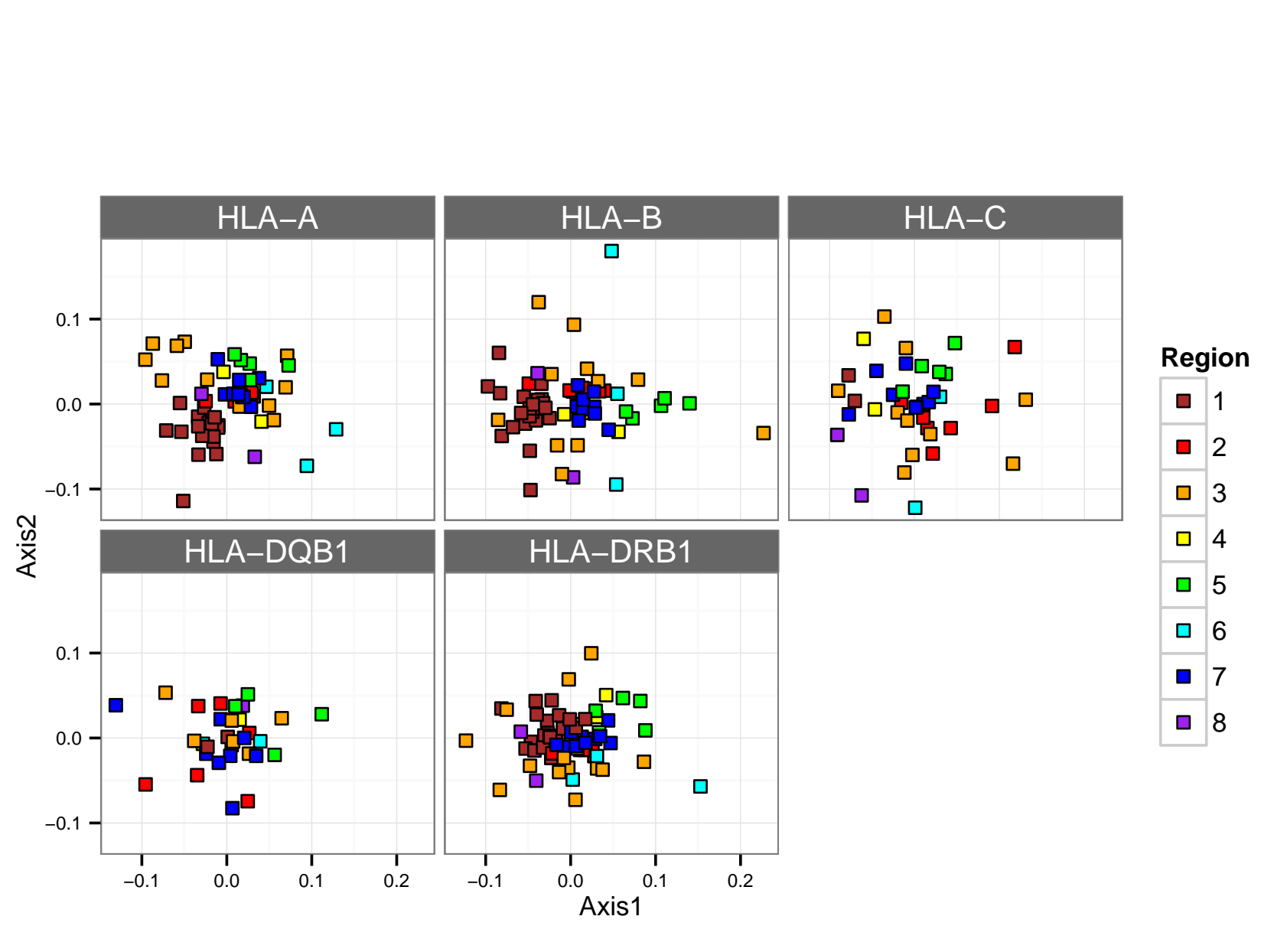

\begin{tabular}{|l|l|}
\hline \multicolumn{1}{|l|}{ Region } \\
\hline$\square$ & 1 \\
\hline$\square$ & 2 \\
\hline$\square$ & 3 \\
\hline$\square$ & 4 \\
\hline$\square$ & 5 \\
\hline$\square$ & 6 \\
\hline$\square$ & 7 \\
\hline$\square$ & 8 \\
\hline
\end{tabular}

$(2+2$

.
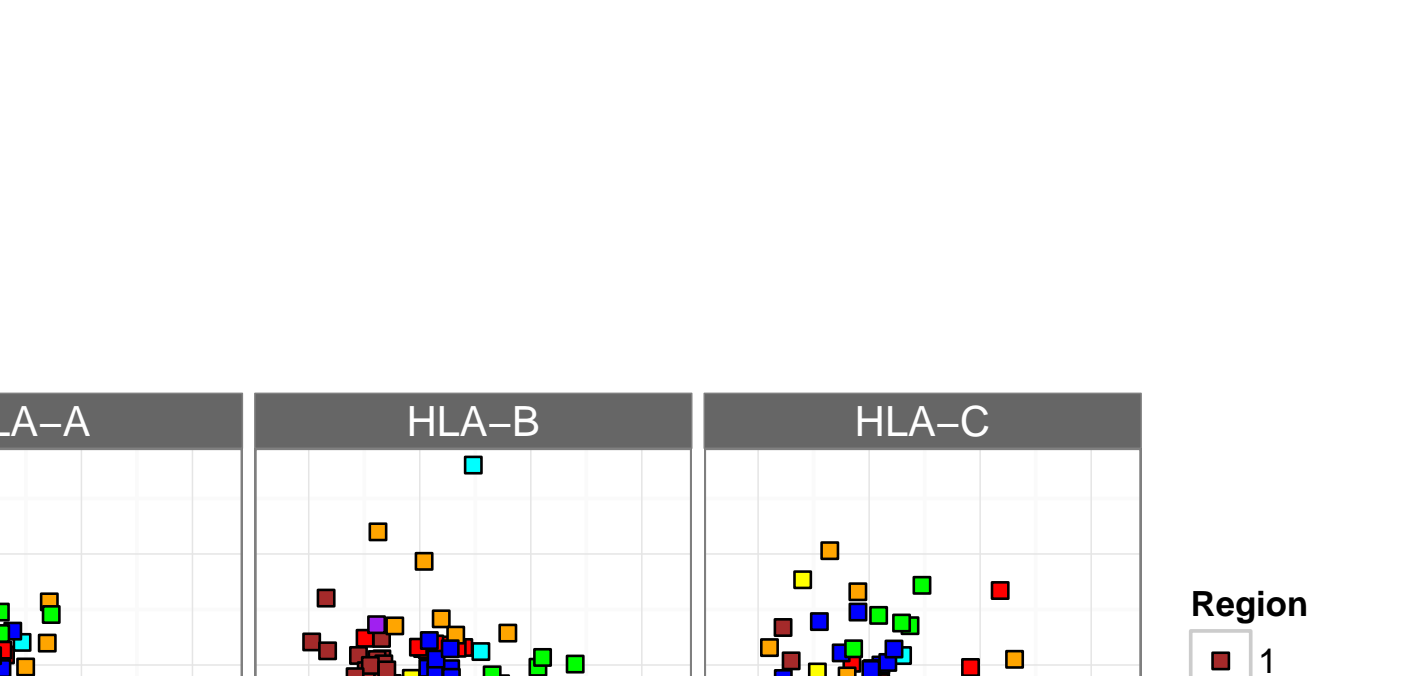

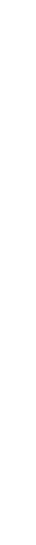


Table 1 Correlation between expected heterozygosity (a), allele frequencies (b), NMDS axes (c) and geographic coordinates (latitude and longitude, respectively)

a)

\begin{tabular}{lcccc}
\hline $\mathrm{H}_{\text {exp }}{ }^{\%}$ & r_latitude & p_latitude & r_longitude & p_longitude \\
\hline HLA-A & -0.309 & 0.016 & 0.182 & 0.160 \\
HLA-B & -0.477 & $\mathbf{0 . 0 0 0 1}$ & -0.288 & 0.024 \\
HLA-C & -0.596 & $\mathbf{9 . 9 E - 0 5}$ & -0.036 & 0.834 \\
HLA-DRB1 & -0.307 & 0.013 & -0.519 & $\mathbf{9 . 3 E - 0 6}$ \\
HLA-DQB1 & 0.269 & 0.150 & -0.091 & 0.631 \\
\hline
\end{tabular}

$\%$ : Excluding the Canary Islands from the analysis.

s: unadjusted $p$-values (in bold when significant after Bonferroni's correction). $\mathrm{H}_{\text {exp }}$ : expected heterozygosity.

b)

\begin{tabular}{|c|c|c|c|c|}
\hline Allele $^{\%}$ & $r \_$atitude & $\mathrm{p} \_$_atitude $\#$ & $r \_$_ongitude & p_longitude $\#$ \\
\hline$A^{*} 23$ & -0.007 & 1 & -0.612 & $3.1 \mathrm{E}-06$ \\
\hline$A^{*} 24$ & -0.401 & 0.023 & -0.303 & 0.282 \\
\hline$A^{\star} 29$ & 0.069 & 1 & 0.744 & 1.3E-10 \\
\hline$A^{*} 30$ & -0.085 & 1 & 0.808 & $7.8 \mathrm{E}-14$ \\
\hline$A * 32$ & -0.182 & 1 & -0.461 & 0.003 \\
\hline$A^{*} 68$ & -0.157 & 1 & -0.638 & $6.2 \mathrm{E}-07$ \\
\hline $\mathrm{B}^{*} 07$ & 0.274 & 0.391 & 0.608 & 5.0E-06 \\
\hline$B^{*} 14$ & -0.191 & 0.846 & -0.507 & 0.0007 \\
\hline $\mathrm{B}^{*} 18$ & -0.239 & 0.635 & 0.636 & 1.0E-06 \\
\hline$B^{*} 27$ & 0.484 & 0.002 & 0.253 & 0.539 \\
\hline $\mathrm{B}^{*} 35$ & -0.217 & 0.651 & -0.434 & 0.009 \\
\hline$B^{*} 38$ & -0.537 & 0.0002 & 0.385 & 0.039 \\
\hline$B * 40$ & 0.239 & 0.635 & 0.464 & 0.003 \\
\hline$B * 44$ & 0.350 & 0.098 & 0.488 & 0.001 \\
\hline$B^{*} 50$ & -0.184 & 0.846 & -0.610 & 4.6E-06 \\
\hline$B^{*} 51$ & -0.026 & 1 & -0.666 & 1.3E-07 \\
\hline$C^{*} 07$ & 0.550 & 0.010 & 0.050 & 1 \\
\hline$C^{*} 12$ & -0.622 & 0.001 & -0.074 & 1 \\
\hline DRB1*03 & -0.307 & 0.091 & 0.463 & 0.002 \\
\hline DRB1*04 & 0.084 & 1 & -0.348 & 0.045 \\
\hline $\mathrm{DRB} 1{ }^{*} 07$ & 0.366 & 0.030 & 0.484 & 0.0007 \\
\hline DRB1*08 & 0.338 & 0.052 & -0.399 & 0.013 \\
\hline DRB1*11 & -0.498 & 0.0004 & 0.224 & 0.300 \\
\hline $\mathrm{DRB}^{*}{ }^{*} 13$ & -0.296 & 0.100 & -0.611 & 1.1E-06 \\
\hline DRB1*14 & -0.389 & 0.016 & -0.031 & 1 \\
\hline DRB1*15 & 0.319 & 0.076 & 0.427 & 0.005 \\
\hline
\end{tabular}

${ }^{\%}$ : the analysis was limited to the alleles reaching a frequency of $5 \%$ in at least one province or district (excluding the Canary Islands from the analysis). Only the alleles showing a significant (adjusted) Spearman's correlation coefficient with latitude and/or longitude are shown here. 
\#: the p-values were adjusted with the Holm's method at each locus separately.

c)

\begin{tabular}{llcccc}
\hline Locus & NMDS $^{\%}$ & r_latitude & p_latitude & r_longitude & p_longitude \\
\hline \multirow{2}{*}{ HLA-A } & Axis1 & 0.016 & 0.899 & 0.579 & $\mathbf{6 . 7 E}-07$ \\
\multirow{2}{*}{ HLA-B } & Axis2 & 0.098 & 0.444 & 0.573 & $\mathbf{9 . 4 E - 0 7}$ \\
& Axis1 & 0.170 & 0.182 & 0.732 & $\mathbf{9 . 3 E - 1 2}$ \\
\multirow{2}{*}{ HLA-C } & Axis2 & -0.323 & 0.010 & 0.143 & 0.263 \\
\multirow{2}{*}{ HLA-DRB1 } & Axis1 & -0.253 & 0.120 & 0.313 & 0.053 \\
\multirow{2}{*}{ HLA-DQB1 } & Axis2 & 0.578 & $\mathbf{0 . 0 0 0 1}$ & 0.347 & 0.030 \\
& Axis1 & 0.273 & 0.025 & 0.666 & $\mathbf{7 . 6 E - 1 0}$ \\
& Axis2 & 0.544 & $\mathbf{1 . 9 E}-06$ & -0.182 & 0.140 \\
& Axis1 & 0.096 & 0.606 & 0.093 & 0.617 \\
\hline
\end{tabular}

$\%$ : including the Canary Islands in the analysis.

§: unadjusted p-values (in bold when significant after Bonferroni's correction). 
Table 2 Correlation between genetic and geographic distances

\begin{tabular}{lcccccc} 
& \multicolumn{3}{c}{ Iberian Peninsula } & \multicolumn{3}{c}{ Spain } \\
\cline { 2 - 7 } Locus & N Pops\# & $r$ & $p$ & N Pops\# & $r$ & $p$ \\
\hline A & 61 & 0.229 & $\mathbf{1 E - 0 4}$ & 29 & 0.099 & 0.092 \\
B & 61 & 0.260 & $\mathbf{1 E - 0 4}$ & 29 & 0.210 & $\mathbf{0 . 0 0 1}$ \\
C & 37 & 0.135 & 0.016 & 29 & 0.175 & $\mathbf{0 . 0 0 9}$ \\
DQB1 & 30 & 0.013 & 0.421 & 29 & -0.005 & 0.507 \\
DRB1 & 65 & 0.132 & $\mathbf{0 . 0 0 3}$ & 29 & 0.106 & 0.079 \\
\hline
\end{tabular}

\#: number of provinces (Spain) and districts (Portugal) included in the analysis; HLA-A, B and DRB1 include both Portugal and Spain (Canary Islands excluded), while HLA-C and DQB1 are limited to Spain (Canary Islands excluded). Only the Spanish provinces with data available at all five loci were considered in the right part of the table.

$\mathrm{P}$-values are shown in bold when significant after Bonferroni's correction. 
Table 3 Genetic diversity in the Iberian Peninsula and Spain

\begin{tabular}{|c|c|c|c|c|c|c|c|}
\hline \multirow[b]{2}{*}{ Locus } & \multirow[b]{2}{*}{ N Pops } & \multicolumn{2}{|c|}{ Iberian Peninsula } & \multicolumn{4}{|c|}{ ANOVA ( $n=8$ geographic groups tested) } \\
\hline & & $\mathrm{F}_{\mathrm{ST}}$ & $\mathrm{p}$ & $\mathrm{F}_{\mathrm{CT}}$ & $\mathrm{p}$ & $\mathrm{F}_{\mathrm{SC}}$ & $p$ \\
\hline $\bar{A}$ & 63 & $0.11 \%$ & $<0.001$ & $0.13 \%$ & $<0.001$ & $0.04 \%$ & $<0.001$ \\
\hline B & 63 & $0.16 \%$ & $<0.001$ & $0.19 \%$ & $<0.001$ & $0.05 \%$ & $<0.001$ \\
\hline C & 39 & $0.15 \%$ & $<0.001$ & $0.11 \%$ & $<0.001$ & $0.06 \%$ & $<0.001$ \\
\hline DQB1 & 31 & $0.11 \%$ & $<0.001$ & $0.00 \%$ & 0.41 & $0.16 \%$ & $<0.001$ \\
\hline DRB1 & 67 & $0.12 \%$ & $<0.001$ & $0.10 \%$ & $<0.001$ & $0.05 \%$ & $<0.001$ \\
\hline
\end{tabular}

N Pops: number of provinces (Spain) and districts (Portugal) included in the analysis; HLA-A, B and DRB1 include both Portugal and Spain, while HLA-C and DQB1 are limited to Spain.

\begin{tabular}{lcccccccc} 
& & \multicolumn{2}{c}{ Spain } & \multicolumn{3}{c}{ ANOVA $(\mathrm{n}=8$ geographic groups tested) } \\
\cline { 2 - 7 } Locus & $\mathrm{N}$ Pops & $\mathrm{F}_{\mathrm{ST}}$ & $\mathrm{p}$ & $\mathrm{F}_{\mathrm{CT}}$ & $\mathrm{p}$ & $\mathrm{F}_{\mathrm{SC}}$ & $\mathrm{p}$ \\
\hline $\mathrm{A}$ & 30 & $0.09 \%$ & $<0.001$ & $0.06 \%$ & $<0.001$ & $0.05 \%$ & $<0.001$ \\
$\mathrm{~B}$ & 30 & $0.13 \%$ & $<0.001$ & $0.11 \%$ & $<0.001$ & $0.04 \%$ & $<0.001$ \\
$\mathrm{C}$ & 30 & $0.14 \%$ & $<0.001$ & $0.12 \%$ & $<0.001$ & $0.05 \%$ & 0.00505 \\
DQB1 & 30 & $0.20 \%$ & $<0.001$ & $0.00 \%$ & 0.37693 & $0.20 \%$ & 0.0002 \\
DRB1 & 30 & $0.11 \%$ & $<0.001$ & $0.08 \%$ & $<0.001$ & $0.05 \%$ & $<0.001$ \\
\hline
\end{tabular}

N Pops: number of provinces (Spain) included in the analysis; only the provinces with data available at all five loci were considered. 